\title{
NOTICIÁRIO NACIONAL
}

\section{Curso de Extensão Universitária em Bioquimica}

Realiza-se a partir de 19/3/79, um curso de extensão universitária em Bioquimica. Para informaçōes complementares contactar Margarida Correia, Secretária do Departamento de Biologia e Bioengenharia da UNL, Centro de Quimica Estrutural, Complexo I, Instituto Superior Técnico, Av. Rovisco Pais, 1000 Lisboa, Telefone: 572616.

\section{Conferências sobre Microbiologia Industrial}

Prof. Dr. Anthony Rose

Laboratório de Microbiologia

Un. de Bath - Inglaterra

Durante a sua próxima vida a Portugal, o Prof. Dr. Anthony Rose proferirá uma série de Conferências que têm o patrocinio das Sociedades Portuguesas de Bioquimica e Microbiologia e que ficam, deste modo, abertas à participação de todos os seus associados. As conferências terão lugar no Auditório do Instituto Gulbenkian de Ciência, em Oeiras, nos dias e horas a seguir indicados:

28.5.79 - 9h 30 - Introduction: emphasis on principies $11 \mathrm{~h} 30$ - Production of beers and wines

29.5 .79 - 9h 30 - Distilled Spirits $11 \mathrm{~h} 30$ - Solvents, acids, nucleotides

30.5 .79 - 9h 30 - Lipids, vitamins and polysaccharides $11 \mathrm{~h} 30$ - Antibiotics

31.5 .79 - 9h 30 - Other secondary products $11 \mathrm{~h} 30$ - Microbial biomass (SCP)

1.6 .79 - 9h $30-$ Enzymes 11h 30 - Transformations

3. Nato Advanted Study Institute - Physics and Chemistry of Low Dimensional Solids

26 de Agosto - 7 de Setembro, 1979, Hotel dos Templários, Tomar - Portugal.

Para informações complementares contactar: Prof. Luis Alcácer, Laboratório de Fisica e Engenharia Nucleares, Apartado 21, 2685 Sacavém, Portugal,

Telex: 12727 NUCLAB P

Telefone: 2510021

\section{Metal lons in Biology - NATO Advanced Study Institute}

Realiza-se de 17 a 29 de Setembro de 1979, no Hotel dos Templários de Tomar.

Participação limitada a 80 pessoas. Para informações com. plementares contactar: Prof. A.V. Xavier, Centro de Quimica
Estrutural, Complexo I, Instituto Superior Técnico, Av. Rovisco Pais, 1000, Lisboa, Portugal.

\section{Simpósio Nacional de Ciências e Tecnologia para o desen} volvimento - SINACT

Organizado pela Junta Nacional de Investigação Cientifica e Tecnológica realizou-se em Maio de 1979, integrado nas actividades preparatórias da participação portuguesa na Conferência das Naçð̃es Unidas sobre Ciência e Tecnologia para o desenvolvimento (UNCSTD).

6. Conferência Mundial de Espectroscopia - World Spectroscopy Conference

Julho 2-3, 1979, Sheraton Hotel, Lisboa - Portugal.

Lingua oficial: Inglês. Inscrição até 30 de Março de 1979: US\$150 por pessoa.

Inscrição após 30 de Março de 1979: US\$200 por pessoa. Autores de comunicaçōes US100 por pessoa.

Orientadores das sessões: N.V. Joshi (University of Oxford, Oxford, Inglaterra);

Pham-Van-Thoai (Centre de Études Nucléaires de Seclay, Gif-sur-Yvette, (França);

Vlado Valkovic ("Ruder Boskovic" Institute, Zagreb, Jugoslávia).

Fuat Bayrakçeken (Middle East Technical University, Ankara, Turquia).

Todas as indicações complementares podem ser obtidas de V.M. Bhatnagar, Alena Entreprises of Canada, P.O. Box 1779 Cornwall, Ontário, K6H 5V7, Canada. Telefone (613) 932-7702.

\section{2." Conferência Mundial de Cromatologia - 2nd World Chromatography Coneference}

Julho 5-6, 1979, Sheraton Hotel, Lisboa - Portugal. Lingua oficial: inglês.

Inscrição até 15 de Março de 1979: US\$150 por pessoa. Inscrição após 15 de Março de 1979: US\$200 por pessoa. Autores das comunicaçōes: US\$100 por pessoa.

\section{Orientadores das sessões:}

A.M. Reid (British Aerospace Stevenage, England); M. Picer ("Ruder Boskovic", Institute, Zagreb, Jugoslávia); R. Muzzarelli (Universidade de Ancona, Ancona, Itália). K. Chan (Liverpool Polytechnic, Liverpool, Inglaterra).

Todas as informações complementares podem ser obtidas de V.M. Bhatnagar, Alena Enterprises of Canada - P.O. Boz 1779, Cornwall, Ontario KGH 5 V7 Canada, Telefone (613) 932 7702. 